\title{
Análise epidemiológica da infecção pelo vírus da cinomose, em cães do município de Garanhuns, Pernambuco, Brasil
}

\section{Analysis of infection epidemiological distemper virus, dogs in the municipality of Garanhuns, Pernambuco, Brazil}

\author{
Érica Chaves Lúcio ${ }^{1 *}$; Juliana de Lima Pimentel²; \\ Saruanna Millena dos Santos Clemente ${ }^{3}$; Acidália Claudino Machado ${ }^{4}$; \\ Júnior Mário Baltazar de Oliveira ${ }^{5}$; Daniel Friguglietti Brandespim ${ }^{6}$; \\ José Lopes da Silva Júnior ${ }^{7}$; José Wilton Pinheiro Júnior ${ }^{8}$
}

\section{Resumo}

A cinomose é causada por Morbilivirus e tem distribuição mundial, sendo o cão o principal reservatório para o vírus. A transmissão ocorre através de aerossóis sendo que este pode ser excretado no fim da fase aguda. Trata-se de uma doença sem predileção por raça, idade ou sexo, no entanto a literatura cita que filhotes são mais acometidos. No estudo realizado foram analisadas amostras de soro de cães domiciliados, nos bairros do município de Garanhuns sendo os bairros escolhidos a Boa Vista, Cohab 1, Cohab 2, Magano e Centro, durante o período de agosto a dezembro de 2012. Foram coletadas amostras de cães com idade superior a três meses, não vacinados contra a cinomose. Para elaboração dos mapas de distribuição geográfica dos animais foram coletadas coordenadas em cada casa visitada para a coleta. Das amostras analisadas, $90,38 \%$ foram positivas, sendo que $28,72 \%$ apresentaram concentração alta de anticorpos, $47,88 \%$ concentração média e $23,40 \%$ concentração baixa. Ao analisar a distribuição por bairros observou-se uma maior prevalência da infecção nos bairros Cohab 2 com 100,00\% e Cohab 1 com 96,00\%; seguido do bairro Boa Vista com 93,10\%; Magano com 78,26\%; Centro com 50,00\%. Neste estudo não foi identificada nenhuma variável associada à infecção referente ao sexo, pois foram acometidos tanto machos quanto fêmeas e $100,0 \%$ dos animais, incluindo positivos e negativos, não eram castrados. Foi evidenciado que $75,0 \%$ dos animais nunca tinham sido levados ao veterinário, e destes, $94,8 \%$ foram positivos, fato este que pode estar relacionado à maior soropositividade nestes animais. Os resultados obtidos nesse estudo mostram que o vírus da cinomose canina encontra-se disseminado na população canina de Garanhuns, Pernambuco, destaca-se a importância de estudos epidemiológicos para a caracterização da real situação da infecção por este vírus nas populações caninas, com o intuito de reduzir os prejuízos à saúde animal provocados pelo agente.

Palavras-chave: Cinomose, cães, Garanhuns, infecção

\footnotetext{
${ }^{1}$ Discente do Programa de Pós-graduação em Ciência Animal Tropical, Universidade Federal Rural de Pernambuco, UFRPE, Campus de Dois Irmãos, Recife, PE. E-mail: erica.c.1@hotmail.com

${ }^{2}$ Discente do Programa de pós-graduação em Saúde Pública, Universidade de Pernambuco, UPE, Garanhuns, PE. E-mail: julianalp. vet@hotmail.com

${ }^{3}$ Médica Veterinária do Laboratório de Diagnóstico Animal, LADA, Madalena, Recife, PE. E-mail: saruannamillena@hotmail. com

${ }^{4}$ Médica Veterinária M.e em Sanidade e Reprodução de Ruminantes, Unidade Acadêmica de Garanhuns, UFRPE, Garanhuns, PE. E-mail: acidali@hotmail.com

${ }^{5}$ Discente do Programa de Pós-graduação em Ciência Veterinária, UFRPE, Campus de Dois Irmãos, Recife, PE. E-mail: jrmariovet@yahoo.com.br

${ }^{6}$ Prof. de Epidemiologia e Saúde Pública, Unidade Acadêmica de Garanhuns, UFRPE, Garanhuns, PE. E-mail: daniel@uag.ufrpe.br

${ }^{7}$ Fiscal da Agência de Defesa Agropecuária de Pernambuco, Recife, PE. E-mail: joselopes@adagro.pe.gov.br

${ }^{8}$ Bolsista de Produtividade, CNPq, Laboratório de Doenças Infecto Contagiosas, Unidade Acadêmica de Garanhuns, UFRPE, Garanhuns, PE. E-mail: jrwilton@uag.ufrpe.br

* Autor para correspondência
} 


\begin{abstract}
Distemper is caused by a Morbillivirus and has worldwide distribution, the dog being the major reservoir for this virus. Transmission occurs by aerosols and the virus can be excreted at the end of the acute phase. It is a disease with no predilection for race, age or sex; however the literature suggests that puppies are most affected. In this study were analyzed serum samples from pet dogs in the city districts and neighborhoods of Garanhuns Boa Vista, Cohab 1, Cohab 2, Magano and center during the period from August to December 2012. Samples were collected from dogs older than three months, not vaccinated against distemper. To produce the maps of geographical distribution of animals were collected coordinates for each home visit. Of the samples analyzed, $90.38 \%$ were positive, and $28.72 \%$ had high antibody concentration, $47.88 \%$ and $23.40 \%$ average concentration or low. By analyzing the distribution by districts observed a higher prevalence of infection in neighborhoods with Cohab $2100.00 \%$ and Cohab 1 with $96.00 \%$; Boa Vista with $93.10 \%$; Magano with $78.26 \%$; center with $50.00 \%$. This study did not identify any variable associated with infection related to sex and $100.0 \%$ of the animals, including positive and negative, were not castrated. It was shown that $75.0 \%$ of the animals had never been taken to the veterinarian, and of these, $94.8 \%$ were positive, a fact that may be related to higher seropositivity in these animals. The results of this study show that the canine distemper virus is widespread in the canine population of Garanhuns, Pernambuco, highlights the importance of epidemiological studies to characterize the real situation of infection by this virus in canine populations, in order to reduce damage to animal health caused by this agent.
\end{abstract}

Key words: Distemper, prevalence, risk factor distribution

\section{Introdução}

A cinomose é uma doença infecto-contagiosa, sendo causada por Morbillivirus, pertencente à família Paramyxoviridae, de distribuição mundial (APPEL; SUMMERS, 1999). O cão é o principal reservatório para o vírus e atua como fonte de infecção para outras espécies e a transmissão ocorre principalmente por aerossóis e pode ser excretado na urina por até três meses após o final da fase aguda da infecção (GREENE; APPEL, 2006).

Estudos no Brasil foram realizados para determinar a prevalência da infecção pelo vírus da cinomose em cães e houve variação de 10,6\% a $65,7 \%$ de soropositividade (CURI, 2005; DEZENGRINI, 2006; BARBOSA; PASSOS, 2008; HASS et al., 2008). Pesquisas indicam maior ocorrência da doença em épocas que a temperatura se encontra mais baixa (HEADLEY; GRAÇA, 2000; BORBA et al., 2002). A doença pode ocorrer em qualquer raça, idade e sexo, mas, os filhotes são mais frequentemente acometidos, com idade variando entre três e seis meses (JOZWIK;
FRIMUS, 2002; NORRIS et al., 2006). Santos (2011) observou que cães não vacinados apresentam maior susceptibilidade à infecção pelo VCC (vírus da cinomose canina).

A cinomose canina foi considerada como uma enfermidade emergente (MARTINO et al., 2004). $\mathrm{O}$ seu entendimento torna-se necessário para o aprimoramento de medidas que impeçam o avanço nas populações de canídeos, tanto domésticos quanto selvagens (MARTINS; LOPES; FRANÇA, 2009).

O sistema de informação georreferenciado contribui para a coleta dos dados em saúde, geração e confirmação de hipóteses, além da tomada de decisões de caráter preventivo (TIM, 1995). O padrão de distribuição espacial de determinada doença permite interferir em alguns aspectos, tal como a forma de contágio e sua difusão na localidade (ACHAN; SZYFRES, 2003).

Objetivou-se com o presente trabalho realizar um estudo epidemiológico da infecção pelo vírus da cinomose em cães no município de Garanhuns, Pernambuco, Brasil. 


\section{Material e Métodos}

Área de estudo

Foram analisadas amostras de soro de cães domiciliados, nos bairros do município de Garanhuns: Boa Vista, Cohab 1, Cohab 2, Magano e Centro, no período de agosto a dezembro de 2012. A distribuição por bairro foi realizada desta forma para proporcionar uma análise representativa de todo o município de Garanhuns.

\section{Amostragem}

Realizou-se um estudo transversal, com amostragem não probabilística por conveniência por meio da metodologia recomendada pelo Centro Panamericano de Zoonosis (1979), onde foi utilizada a fórmula:

$$
\mathrm{N}=\mathrm{P} \cdot(100-\mathrm{P}) \cdot \mathrm{\alpha}^{2} /(\mathrm{d})^{2}
$$

Onde:

$\mathrm{N}=$ número da amostra; $\mathrm{P}=$ prevalência esperada; $\alpha=$ nível de confiança; d=erro admissível (em valor absoluto \%).

Para esse estudo foi considerada a prevalência de 27,3\% (DEZENGRINI, 2006), intervalo de confiança de $95 \%$ e margem de erro de $10 \%$. Desta forma o tamanho total da amostra foi de 67 animais e para aumentar a margem de segurança foram coletadas 104 amostras.

\section{Coleta de material biológico}

Foram coletadas amostras de cães com idade superior a três meses, não vacinados contra a cinomose. A coleta se fez por punção de veia cefálica ou safena, após a antissepsia com solução de álcool iodado a $2 \%$ e aproximadamente $2 \mathrm{~mL}$ de sangue foram coletados em tubos esterilizados sem anticoagulante para a obtenção de soro. Posteriormente as amostras devidamente identificadas foram encaminhadas ao Centro Laboratorial de Apoio à Pesquisa (CENLAG) da
Unidade Acadêmica de Garanhuns, Universidade Federal Rural de Pernambuco. Para obtenção do soro as amostras foram centrifugadas por 10 minutos a 5000rpm e o soro obtido foi armazenado em microtubos e submetido a congelamento a $-20^{\circ} \mathrm{C}$ até seu processamento.

\section{Detecção de anticorpos anti-virus da Cinomose}

As amostras de soro sanguíneo foram submetidas à reação de imunocromatografia, sendo a concentração de anticorpos para o vírus da cinomose considerada alta acima de 1:128, média de 1:16 a 1:64 e baixa de 1:16 ou menor que isso, conforme a metodologia descrita pelo Kit Bioeasy ${ }^{\circledR}$.

\section{Distribuição espacial}

Para elaboração dos mapas de distribuição geográfica dos animais (positivos e negativos) foram coletadas coordenadas na projeção Universal Transversal Mercator (UTM) em cada casa visitada com o auxílio de um equipamento GPS (Global Position System). Os dados georreferenciados foram lançados nos aplicativos Quantum GIS (QGIS versão 1.8) para elaboração da figura.

\section{Análise estatistica}

Foi utilizada análise estatística descritiva para cálculo das frequências relativa e absoluta dos resultados obtidos no teste sorológico. Para identificar os fatores de risco associados à infecção pelo vírus da cinomose foi realizada uma análise univariada das variáveis de interesse através do teste qui-quadrado de Pearson, ou Exato de Fisher, quando necessário. As variáveis independentes ou explanatórias consideradas no modelo foram aquelas que apresentaram significância estatística $<0,20$. Essa probabilidade foi estipulada para que possíveis fatores de risco do evento não fossem excluídos da análise. Para execução dos cálculos estatísticos utilizou-se o programa Epi Info 7.0. 


\section{Resultados e Discussão}

Das amostras analisadas, 90,38\% (94/104) foram positivas e destas, 28,72\% (27/94) apresentaram concentração alta de anticorpos, 47,88\% (45/94) concentração média e 23,40\% (22/94) concentração baixa, observando-se portanto, uma alta prevalência da infecção pelo vírus da cinomose no município de Garanhuns. Resultados diferentes foram encontrados por Barbosa e Passos (2008) em Anápolis-Goiás, onde apenas 10,6\% (49/460) dos cães foram positivos para infecção pelo vírus da cinomose. Já Dezengrini (2006) relatou uma prevalência na cidade de Santa Maria - Rio Grande do Sul de 27,3\% (223/817). Levantamento realizado por Curi (2005) em cães domiciliados de Minas Gerais, na região da Serra do Cipó, demonstrou $65,7 \%$ de positividade, com titulação considerada alta. As diferenças entre os resultados deste estudo e os supracitados podem estar relacionadas ao delineamento amostral e possíveis variações na sensibilidade e especificidade dos métodos de diagnóstico empregados.
A distribuição espacial encontra-se disposta na Figura 1. Ao analisar a distribuição por bairros observou-se uma maior prevalência da infecção nos bairros Cohab 2 com 100,00\% (23/23) e Cohab 1 com 96,00\% (24/25); Boa Vista com 93,10\% (27/29); Magano com 78,26\% (18/23); Centro com $50,00 \%(2 / 4)$. Essa maior prevalência nos bairros Cohab 1 e 2 e Boa Vista pode estar relacionada às condições socioeconômicas e o nível de informação, pois muitos proprietários não levavam seus cães a veterinários e nem possuíam informações sobre a doença e vacinas existentes para prevenção da cinomose. Outro fato que pode estar relacionado a essa maior positividade é o número de cães de mobilidade irrestrita observado próximo as residências durante as coletas, pois de acordo com Borba et al. (2002) os cães de mobilidade irrestrita não são bem cuidados e apresentam uma maior susceptibilidade de entrar em contato com partículas de outros cães já infectados e disseminar o vírus no ambiente.

Figura 1. Distribuição espacial da infecção pelo vírus da cinomose em cães no município de Garanhuns, PE.

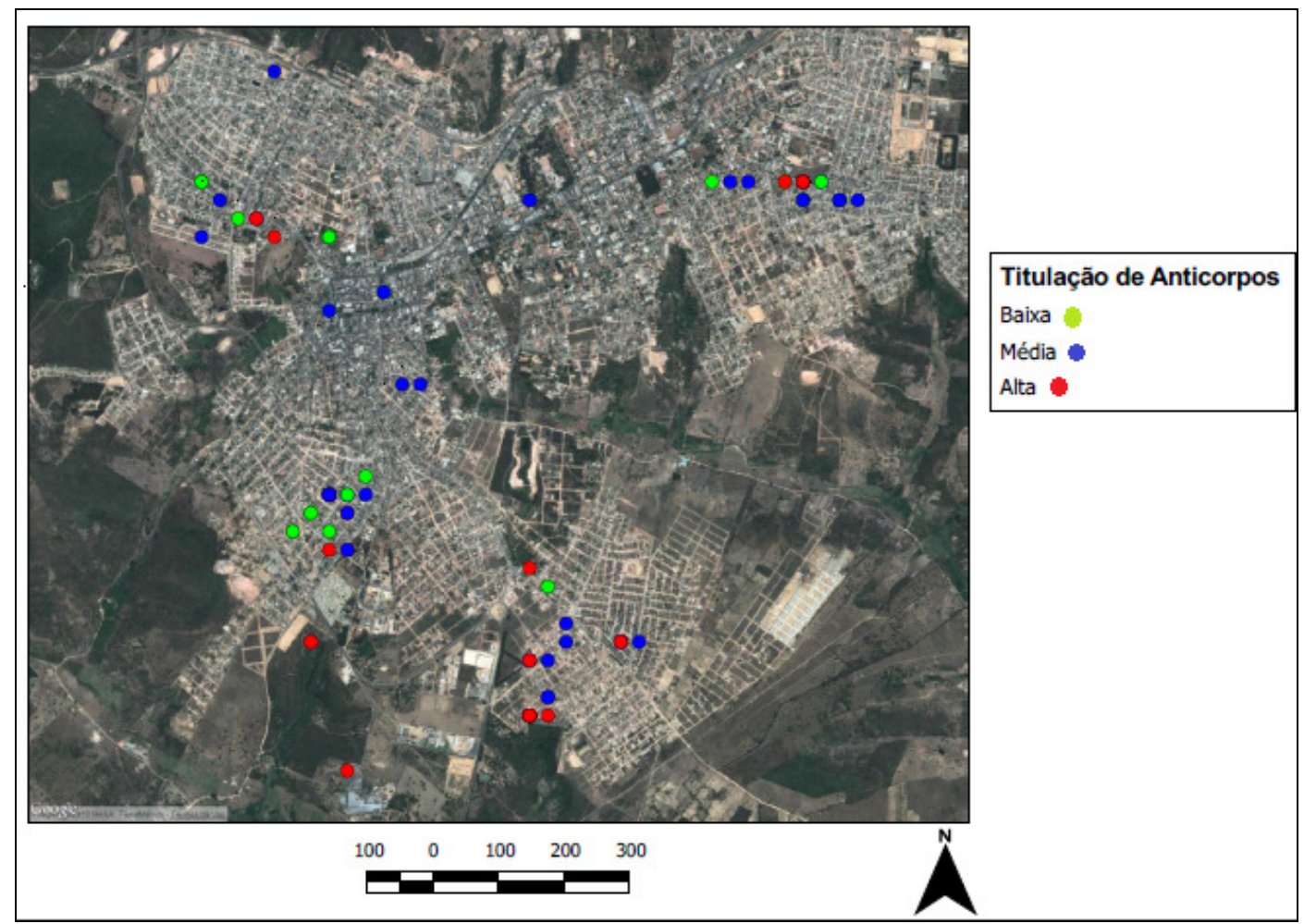

Fonte: Elaboração dos autores. 
O bairro que apresentou um menor número de animais positivos foi o Centro, pela quantidade menor de amostras coletadas, pois os proprietários possuíam uma resistência para coleta de material biológico.

Os resultados dos fatores relacionados à infecção pelo vírus da cinomose encontram-se dispostos na tabela 1. Não foi identificada neste estudo nenhuma variável associada à infecção referente ao sexo, pois foram acometidos tanto machos quanto fêmeas, resultados semelhantes foram encontrados em diversos estudos (PATRONEK et al., 1995; HEADLEY; GRAÇA, 2000; BORBA et al., 2002).

Tabela 1. Pesquisa de anticorpos e análise de fatores de risco associados à infecção pelo vírus da cinomose em cães, no município de Garanhuns, Pernambuco, Brasil, 2012.

\begin{tabular}{|c|c|c|c|c|c|}
\hline \multirow{2}{*}{ Variáveis } & \multirow{2}{*}{$\mathbf{n}$} & \multicolumn{2}{|c|}{ Sorologia } & \multirow{2}{*}{ OR } & \multirow[b]{2}{*}{ Valor de $p$} \\
\hline & & $\begin{array}{c}\text { Positivos } \\
\text { F.A. }\end{array}$ & $\begin{array}{l}\text { Positivos } \\
\text { F.R. (\%) }\end{array}$ & & \\
\hline \multicolumn{6}{|c|}{ Contato com outros cães } \\
\hline $\operatorname{Sim}$ & 53 & 51 & 96,2 & \multirow{2}{*}{3,4} & \multirow{2}{*}{0,156} \\
\hline Não & 51 & 45 & 88,2 & & \\
\hline \multicolumn{6}{|c|}{ Acesso à rua } \\
\hline Sim & 67 & 64 & 95,5 & \multirow{2}{*}{3,3} & \multirow{2}{*}{0,129} \\
\hline Não & 37 & 32 & 86,4 & & \\
\hline \multicolumn{6}{|c|}{ Visita ao veterinário } \\
\hline Sim & 26 & 22 & 84,6 & \multirow{2}{*}{0,2} & \multirow{2}{*}{0,105} \\
\hline Não & 78 & 74 & 94,8 & & \\
\hline \multicolumn{6}{|l|}{ Sexo } \\
\hline Macho & 57 & 51 & 89,4 & \multirow{2}{*}{0,4} & \multirow{2}{*}{0,288} \\
\hline Fêmea & 47 & 45 & 95,7 & & \\
\hline \multicolumn{6}{|c|}{ Animais castrados } \\
\hline $\operatorname{Sim}$ & - & - & - & \multirow{2}{*}{-} & \multirow{2}{*}{-} \\
\hline Não & 104 & 96 & 92,3 & & \\
\hline
\end{tabular}

$\mathrm{OR}=$ Odds Ratio, $\mathrm{n}=$ número de animais, F.A. (Frequência absoluta), F.R. (Frequncia Relativa)

Fonte: Elaboração dos autores.

Observou-se que 100,0\% dos animais, incluindo positivos e negativos, não eram castrados, talvez por desinteresse do proprietário em função do custo, preconceito ou ainda mesmo por falta de conhecimento, sabe-se que animais não castrados são mais expostos a agentes virais devido à procura pelo parceiro, que muitas vezes estão infectados e eliminando agentes infecciosos.

Embora o contato com outros cães e o acesso a rua sejam considerados fatores de risco, por facilitar a transmissão do agente causador da cinomose, não foi evidenciando neste estudo uma maior predisposição de animais que se enquadre nesse perfil, provavelmente devido a viés de informação dos proprietários e/ou a intensa disseminação do vírus no município. Constatou-se que muitos proprietários não possuem o hábito de levar o animal ao veterinário, seja por fatores socioeconômicos ou culturais. Foi evidenciado que $75,0 \%$ dos animais nunca tinham sido levados ao veterinário, e destes, $94,8 \%$ foram positivos, fato este que pode estar relacionado à maior soropositividade nestes animais por nunca terem sido levados ao veterinário e portanto, seus proprietários não terem recebido as 
orientações adequadas sobre o controle e prevenção da cinomose canina.

O conhecimento da prevalência, da distribuição espacial e análise dos fatores de risco, pode auxiliar no planejamento de estratégias de controle, incluindo a vacinação. Bohm et al. (2004) afirmou que o uso sistemático de vacinas contra o vírus da cinomose pode reduzir a ocorrência da infecção e a circulação de vírus na população canina.

\section{Conclusões}

Os resultados apresentados nesse estudo indicam que o VCC se encontra disseminado na população canina de Garanhuns, Pernambuco. Nesse sentido, sugere-se que a implantação de um programa de vacinação maciça em cães jovens pode contribuir para a redução da circulação do VCC e consequente diminuição da ocorrência da infecção. Desta forma, ressalta-se a importância de estudos epidemiológicos para a caracterização da real situação da infecção por este vírus nas populações caninas, com o intuito de reduzir os prejuízos à saúde animal provocados por este agente.

\section{Agradecimentos}

A empresa Bioeasy pelo fornecimento dos kits de diagnóstico.

\section{Referências}

ACHAN, P. N.; SZYFRES, B. Zoonosis y enfermedades transmisibles comunes al hombre y a los animales. In: Bacteriosis y micosis. 3. ed. Washington: Organización Panamericana de la Salud, 2003. v. 1, p. 175-186. Parte 1.

APPEL, M. J. G.; SUMMERS, B. A. Canine distemper: current status. [S.1: s.n.], 1999. Disponível em: <http:// www.ivis.org/>. 1999. Acesso em: 15 dez. 2012.

BARBOSA, J. M.; PASSOS, R. F. B. Análise dos casos de cinomose no H. V. São Francisco de Assis da Faculdade Latino Americana - Anápolis - Goiás. Ensaios e Ciência: Ciências Biológicas, Agrárias e da Saúde, São Paulo, v. 12, n. 1, p. 139-150, 2008.
BOHM, M.; HERRTAGE, M. E.; THOMPSON, H.; WEIR, A.; HASTED, A. M.; MAXWELL, N. S. Serum antibody titres to canine parvovirus, adenovirus and distemper virus in dogs in the UK wich had not been vaccinated for at least three years. Veterinary Record, London, v. 154, n. 15, p. 457-463, 2004.

BORBA, T. R.; MANNIGEL; R. N.; FRAPORTI, C. K.; HEADLEY, S. A.; SAITO, T. B. Cinomose: dados epidemiológicos Maringá - PR (1998-2001). Iniciação Científica Centro Universitário de Maringá - Cesumar, Maringá, v. 4, n. 1, p. 53-56, 2002.

CURI, N. H. A. Avaliação do estado de saúde e do risco de transmissão de doenças entre canídeos (Mammalia, Carnivora) silvestres e domésticos na região da Serra do Cipó. 2005. Dissertação (Mestrado em Implicações para a Conservação) - Pontifícia Universidade Católica de Minas Gerais, Belo Horizonte.

DEZENGRINI, R. Soroprevalência de infecções víricas em cães de Santa Maria, RS; e seleção e caracterização de linhagens celulares resistentes ao vírus da diarréia viral bovina. 2006. Dissertação (Mestrado em Medicina Veterinária) - Universidade Federal de Santa Maria, Santa Maria.

GREENE, C. E.; APPEL, M. J. Canine distemper. In: GREENE, C. E. (Ed.). Infectious diseases of the dog and cat. $3^{\text {th }}$ ed. St Louis: Elsevier, 2006. p. 25-4.

HASS， R.; JOHANN， J. M.; CAETANO, C. F.; FISCHER, G.; VARGAS, G. D.; VIDOR, T.; HÜBNER, S. O. Níveis de anticorpos contra o vírus da cinomose canina e o parvovírus canino em cães não vacinados e vacinados. Arquivo Brasileiro de Medicina Veterinária e Zootecnia, v. 60, n. 1, p. 270-274, 2008.

HEADLEY, S. A.; GRAÇA, D. L. Canine distemper: epidemiological findings of 250 cases. Brazilian Journal of Veterinary Research and Animal Science, São Paulo, v. 37, n. 2, p. 136-140, 2000.

JOZWIK, A.; FRIMUS, T. Natural distemper in vaccinated and unvaccinated dogs in Warsaw. Journal of Veterinary Medicine Series B-infectious Diseases and Veterinary Public Health, Berlim, v. 49, n. 9, p. 413-414, 2002.

MARTINO, P. E.; MONTENEGRO, J. L.; PREZIOSI, J. A.; VENTURINI, C.; BACIGALUPE, D.; STANCHI, N. O.; BAUTISTA, E. L. Serological survey of selected pathogens of free-ranging foxes in southern Argentina, 1998-2001. Revue Scientifique et Technique - Office International des Epizooties, Paris, v. 23, n. 3, p. 801806, 2004. 
MARTINS, D. B.; LOPES, S. T. A.; FRANÇA, R. T. Cinomose canina - revisão de literatura. Acta Veterinaria Brasilica, Mossoró, v. 3, n. 2, p. 68-76, 2009.

NORRIS, J. M.; KROCKENBERGER, M. B.; BAIRD, A. A.; KNUDSEN, G. Canine distemper: re-emergence of an old enemy. Australian Veterinary Journal, Londres, v. 84, n. 10, p. 362-363, 2006.

PATRONEK, G. J.; GLICKMAN, L. T.; JOHNSON, R.; EMERICK, T. J. Canine distemper infection in pet dogs: II. A case-control study of risk factors during a suspect outbreak in Indiana. Journal of the American Animal Hospital Association, Lakewood, v. 31, n. 3, p. 230-235, 1995.
SANTOS, M. F. B. Prevalência dos principais sinais clínicos em cães suspeitos de cinomose atendidos na clínica médica veterinária, Formiga - MG. 2011. Trabalho (Conclusão do curso de Medicina Veterinária) - Centro Universitário de Formiga, Minas Gerais.

TIM, U. S. The application of GIS in environmental health sciences: opportunities and limitations. Environmental Research, New York, v. 71, n. 2, p. 75-88, 1995. 
